\title{
Design of a semi-autonomous boat for measurements of coastal sedimentation and erosion
}

\author{
DANIEL SMITH, LINDA CROSS, JARED RIVET \& STEVEN HALL \\ Department of Biological and Agricultural Engineering, Louisiana State University Agricultural Center, Baton Rouge, \\ Louisiana 70803, USA \\ shall5@1su.edu
}

\begin{abstract}
Measurement of sediment deposition and erosion in coastal areas is a challenge due to soft shifting sediments, but is critical to assessing loss or restoration of coastal sediments and wetlands. The aim of this project was to design and construct a semi-autonomous boat with water depth measuring capabilities. It was intended to map the depth of coastal wetlands to determine erosion rates and assess coastal restoration effects. Depth-measuring equipment was incorporated into an autonomous pontoon boat powered by solar panels. The propulsion system consisted of two paddlewheels and two-way motors to allow movement and positioning for measurements. Modifications included a lightweight, hard coating on the pontoons and powder-coating the frame to extend their usable life. A microcontroller controlled the boat and captured depth data from sensors and location data with a GPS system. The depth measuring system consisted of a pulley and counter system that completed each measurement in less than 45 seconds. This allowed the boat to take approximately 400 measurements per day. Net accuracy was approximately $3 \mathrm{~cm}$ in the tested configuration. The boat can continually measure the depth of specified areas in the wetlands; with this data, the change in depth can be monitored to see the effects of restoration projects.

Key words sediment measurement; coastal restoration; autonomous; coastal land accretion; monitoring; assessing
\end{abstract}

\section{INTRODUCTION}

Louisiana, like many coastal regions around the world, has been losing land due to erosion, subsidence and sea level rise. In Louisiana, altered hydrology, oil and gas extraction, tropical storms and lack of system sediment have exacerbated the problem (Glick, 2013). Some estimates suggest the loss of 50\% of US wetlands from historical levels (Dahl, 2006). Simultaneously, a variety of techniques have been employed to naturally or artificially enhance sedimentation (Piazza, 2005; Risinger, 2012). These include hardened structures such as bulkheads, revetments, seawalls; as well as biologically or ecologically more friendly techniques (Swann, 2008; LaPeyre et al., 2014; Smith et al., 2014)

In the case of these projects, measurement of erosion reduction and sedimentation, in addition to other physical parameters such as wave energy reduction, and of biological factors such as plant or animal growth, are critical to assessing success. Techniques for measuring changes in soft sediments over time are currently difficult and expensive. One alternative proposed in this paper is a semi-autonomous boat which can traverse shallow coastal waters and repeatedly measure soft sediment surfaces (Fig. 1). Over time, such devices could be used to measure sediment related parameters of numerous coastal areas and restoration projects.

Although originally developed to reduce bird predation on aquaculture ponds (Price et al., 2001, 2006; and Price and Hall, 2002, 2012), the use of autonomous vehicles was proposed previously for applications such as environmental and water quality monitoring (Hall and Price, 2003; Hall et al., 2006). Initial experiments were performed to study the ASV's surroundings through the use of stand-alone-data-logging equipment and sensors that the vehicle was fitted with (Hall et al., 2005, 2006). ASVs were used to scare birds off a drinking water reservoir, in 2007, in an attempt to improve water quality through the reduction of avian faecal material in the drinking water supply (Hall et al., 2007a). An early environmental monitoring experiment was to map nitrate levels in a pond by taking readings with a nitrate sensor at specified intervals while it traversed a random path across the water (Smith, 2011). ASVs can be utilized for a variety of experimental monitoring tasks.

The possible applications of robotic, autonomous, or remote control have been studied by countless researchers. Tang et al. (2000) and Jeon et al. (2009) developed autonomous vehicles for biological engineering applications such as precise weed control. Additionally, Kim et al. (2000) developed an unmanned tractor for agricultural engineering applications. Methods for controlling 


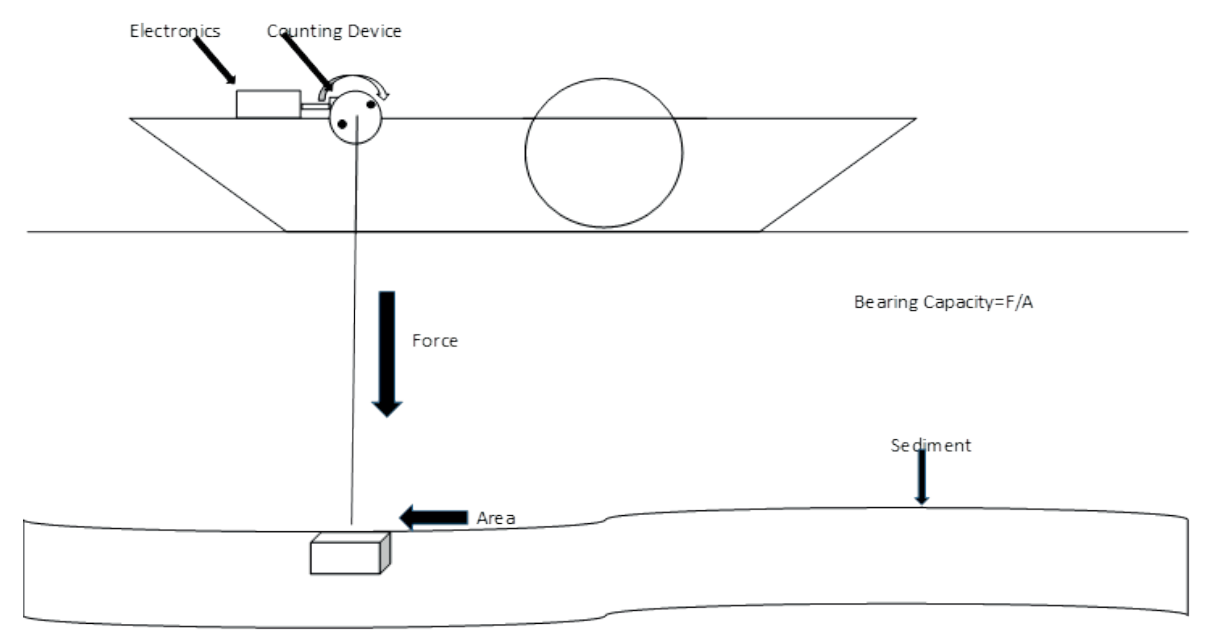

Fig. 1 Autonomous boat for sediment measurement.

these autonomous vehicles through vision systems (Noguchi et al., 1999; Broggi et al., 2000), the application of neural networks for robotic mowers (Wang et al., 2004), and positioning using a simple odometric model (Lindgren et al., 2002) have also been studied.

Depth measurement and mapping techniques have been studied for decades. Side-scan sonar can be used to map underwater terrain. Advanced side-scan sonar applications include determining relationships and patterns from data collected underwater (Damuth et al., 1988). Hoge et al. (1980) used an airborne pulsed neon laser system to accurately measure water depth to within 10 metres. Ground-penetrating radar is a quick noninvasive depth measurement technique that can be utilized to measure and map underwater structures (Gerhards et al., 2008). None of these techniques however, are able to accurately measure water depth along the Louisiana coast due to the soft sediments prevalent.

Some numerical models attempt to predict sediment movement, but effects on sediment redistribution from hurricanes and other storms are not well-accounted for in current models. To assist in monitoring all of these changes, a physical measurement system was constructed. This boat provides an inexpensive alternative for mapping wetlands and coastal areas. It is designed to operate in extremely shallow water, and a fleet of boats could be used to map paired reference areas. The restoration efforts from each area could then be compared by the data provided from these boats.

\section{MATERIALS AND METHODS}

\section{Analysis}

Power, buoyancy, bearing capacity, and tide equations were taken into consideration. The power equation, $\mathrm{P}=\mathrm{VI}=\mathrm{I}^{2} \mathrm{R}$, was used to determine the total amount of power received from the solar panels and how much amperage was available for use. 1-2 amps were available using $12 \mathrm{~V}$ batteries. Approximately 1 amp was required to power all of the components.

Because of the sediment found in the coastal wetlands, the actual bottom can be difficult to determine. Bearing capacity, the amount of force the soil must exert to support a predetermined load, was used to determine the bottom of the body of water. The bearing capacity of soft cohesive soil is approximately $75 \mathrm{kPa}$. Using two triangular fishing weights and a square metal plate that, in total, had a mass of $0.45 \mathrm{~kg}$, a bearing capacity of $3.4 \mathrm{kPa}$ was achieved, providing the ability to measure very low bearing pressure soils.

Tides also influence the depth readings. The tides can be mapped to follow a sinusoidal wave that can be compared to the depth readings from the boat. By comparing the differences of the tidal wave and the depth readings, the actual depth can be found by subtracting the tidal change from the depth reading. 
(a)

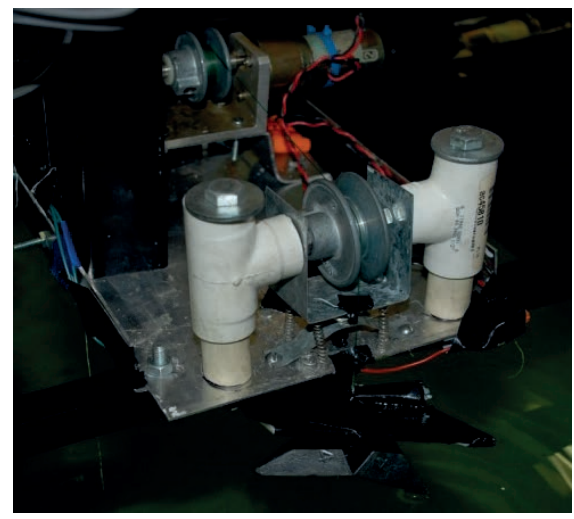

(b)

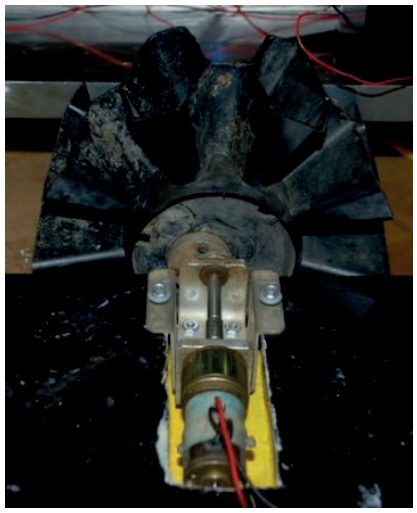

Fig. 2 (a) Assembly of depth measuring device onto aluminium frame for placement on foam pontoons. A metal plate attached to two triangular fishing weights totalling $0.45 \mathrm{~kg}$ is lowered off the end of the platform into the water. (b) The paddlewheel.

A depth measuring device was constructed as shown in Fig. 2(a) and included two spools arranged horizontally with a line running from one of the spools driven by a motor. The system included an aluminium frame attached to two foam pontoons, a sheet of metal as the platform for most of the equipment, the two spools, and brackets and rods to hold the spools. At the end of the line was a $0.45 \mathrm{~kg}$ mass that was lowered into the body of water until it reached the bottom, at which the lack of tension in the string caused a button to be released and thus the motor to stop unwinding the string. The number of revolutions was detected by an infrared sensor across the spool as the string unwound and was directly correlated to the depth of the water, up to $2.5 \mathrm{~cm}$ accuracy. This information was then stored to a USB drive for analysis.

One challenge with soft sediments is that traditional sonar systems cannot accurately define the bottom; even traditional hand techniques are challenging in soft sediments. The boat can be used at high tide to assess subsurface sediment accretion or erosion. Its bearing capacity (force per area) can be customized by altering the area of the bearing plate and the weight of the plate and any weights. The tested device had an area of $13 \mathrm{~cm}^{2}$ and a mass of $0.45 \mathrm{~kg}$, providing a loading of about $4 \mathrm{kPa}$. This is a very low loading. For comparison, soft clays and silts are generally assumed to have a bearing capacity $<75 \mathrm{kPa}$. Thus, the device can identify a very soft bottom as defined by the support at this low bearing capacity $(4 \mathrm{kPa})$, and the specific bearing capacity can be customized by changing the plate area or the mass.

Some sonar systems could differentiate sedimentation levels, but they are not cost effective for this design, and most sonar is not accurate on soft surfaces. A weight attached to a line on a spool with a spring counter was selected as the most feasible solution in measuring depth after using the Pugh selection method.

\section{Components}

An autonomous boat was constructed incorporating a depth measuring device. The boat consisted of foam pontoons and an aluminum frame, with a GPS, microcontroller, and propulsion system powered by batteries and solar panels. The two foam pontoons had dimensions of $20.3 \times 122 \times$ $15.2 \mathrm{~cm}$. The two frames were $86.4 \mathrm{~cm}$ along the base and $67.3 \mathrm{~cm}$ along the top. The frames were $24.1 \mathrm{~cm}$ high and $1.91 \mathrm{~cm}$ thick. The three solar panels had dimensions of $31.5 \times 92.5 \times 1.91 \mathrm{~cm}$ and the two batteries had dimensions of $15 \times 6.4 \times 9.1 \mathrm{~cm}$. The depth measuring device on the autonomous boat consisted of spools controlled by a motor which lowered a weight into the water. The distance the line unwound was detected by an infrared sensor and was used to calculate the depth of the water.

Foam pontoons The two pontoons were constructed from Styrofoam, the blue extruded polystyrene (XPS) foam which has a uniform structure of closed cells and provides high moisture resistance, durability, high buoyancy, and high resistance to rotting and deterioration. Each 
pontoon was $20.3 \times 122 \times 15.2 \mathrm{~cm}$ and was cut to the desired shape using a foam cutter, a heated wire that melted the foam away when applied. Two pieces of foam were glued together using foam glue and spray adhesive to achieve the $15.2 \mathrm{~cm}$ thickness because of foam piece availability. The foam cutter was used to round the ends of the foam to decrease the amount of drag from the water. Then, sandpaper was used to smooth all of the surfaces of the foam. These pontoons had a volume of $0.04 \mathrm{~m}^{3}$, which support about $85.9 \mathrm{lbs}(39 \mathrm{~kg})$ while remaining afloat.

Buoyancy was determined using Archimedes principle to find the maximum weight supportable by the pontoons: $\mathrm{mg} \leq \rho \mathrm{Vg}(\mathrm{Fg} \leq \mathrm{Fb})$, where $\rho_{\text {water }}=1.025 \mathrm{~L} / \mathrm{kg}=0.001025 \mathrm{~m}^{3} / \mathrm{kg}$; $V_{\text {styrofoam }}=0.04 \mathrm{~m}^{3}$; and $\mathrm{m}=0.04 \mathrm{~m}^{3} / 0.001025 \mathrm{~m}^{3}=39.0 \mathrm{~kg} \sim 85.9 \mathrm{lbs}$.

Since the boat needed to function in water for extended periods, and faced exposure to a harsh environment, additional protection was applied to the foam pontoons. A Foam Coat, a hard, crustlike shell for expanded polystyrene, was chosen as a suitable coating that would not melt the foam. Additionally, the coating is lightweight, can be painted, and the foam can be drilled into through it. Spray painting the coating gave additional protection from the water. One final advantage of using this coating was the hard outer shell it created, which prevented damage due to logs or other debris in the wetlands.

Aluminium frame The structure on the boat consisted of two aluminum frames $86.4 \mathrm{~cm}$ along the base and $67.3 \mathrm{~cm}$ along the top. The frame height was $24.1 \mathrm{~cm}$ and was composed of a hollow square that was $1.91 \mathrm{~cm}$ thick. The top and bottom of the frame were separated by two vertical bars $20.3 \mathrm{~cm}$ long welded to each piece. To help prevent corrosion, effects of the harsh environment, and scratches, the aluminum frame was powder coated. The frame was then mounted on the foam pontoons.

Solar panels The autonomous boat and depth measuring device required an adequate power source to run. Two solar panels from Harbor Freight Tools USA Inc., model number 905991VGA, were installed atop the aluminum frame. Each solar panel had a peak power of 15 watts and a maximum current of 1.25 amps. Their peak voltage, 23.57 volts open current, allowed 12 volts to be supplied to each panel. The dimensions of the solar panels were $31.5 \times 92.5 \times 1.91 \mathrm{~cm}$ and they had a mass of $4.4 \mathrm{~kg}$ apiece.

Marine batteries Two Hobbico TorqMaster LC batteries were used to power the electrical components on the boat. These $12 \mathrm{~V}, 7 \mathrm{amp}$ hour capacity batteries have a mass of $2.38 \mathrm{~kg}$ each and are maintenance free, high capacity, and rechargeable. They are $15.0 \times 6.4 \times 9.1 \mathrm{~cm}$ sealed, lead/calcium batteries, which eliminate the need for electrolytes. Many different electrical components powered by the batteries were incorporated into the design. Since the maximum current available under peak sunlight was approximately $2.5 \mathrm{amps}$, the boat electronics were designed to draw less than 1.5 amps maximum leaving adequate current to recharge the batteries.

GPS Electrical components involved in the function of the device included a GPS, the Parallax GPS Datalogger Kit. This GPS is able to track multiple satellites at a time and provide one-second navigation updates. Additionally, it is a low power device, drawing $65 \mathrm{~mA}$ at 12 volts. This GPS includes the capability of FAA Wide Area Augmentation System (WAAS) differential GPS. WAAS allows high accuracy GPS readings within three meters, while standard GPS has an accuracy of around 15 metres.

Microcontroller The microcontroller used, a BASIC Stamp 2e (BS2e), has the capability of handing 4000 calculations per second (Parallax.com). This component draws $25 \mathrm{~mA}$ of current, which was ideal for the limited power available.

Propulsion To properly function, the boat must be self-propelled. A paddle wheel system with two-way motors was installed on the boat for propulsion. The paddle wheel (Fig. 2(b)) was similar in design to the inner workings of a fertilizer spreader. 


\section{Mechanical depth measuring}

The depth-measuring system consisted of a two-way motor lowering and lifting a $0.45 \mathrm{~kg}$ mass on a line via two spools. The $0.45 \mathrm{~kg}$ mass consisted of a metal plate that sat on top of two triangular fishing weights. This reel and pulley system was mounted on a U-shaped bracket on four springs resting on a pushbutton, and functioned by detecting the change in tension in the line. When the weight was lowered, the tension in the line depressed the pushbutton, and when the weight landed on the bottom of the body of water, the button was released from the lack of tension. An infrared detector and emitter were used to measure the amount of line needed to reach the bottom. The IR system was enclosed in a box to block out light, and a metal disk with two equidistant holes was placed between the sensors. The slot created an opening where the detector could receive a signal from the emitter and register a change in voltage. By rotating the disk at the same speed as the reel, the number of voltage changes could be counted. For each half rotation of the disk, $3.8 \mathrm{~cm}$ of depth were measured. The mechanical depth-measuring device is designed for depths of up to $4 \mathrm{~m}$. The schematic of electronic components of the depth-measuring device is shown in Fig. 3.

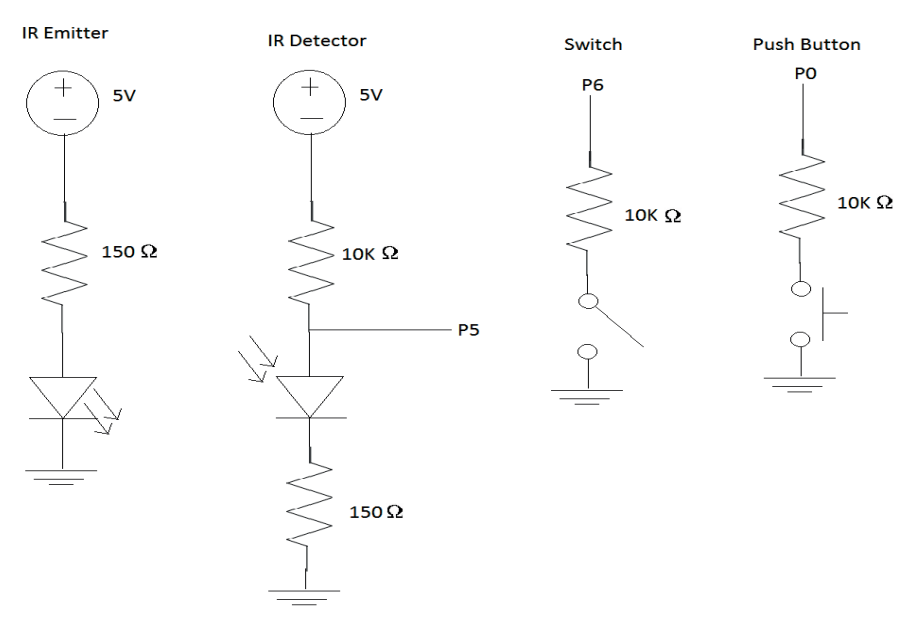

Fig. 3 Schematic of IR system, switch, and push button.

\section{Programming}

The program running on the BASIC Stamp controlled the boat's movement and data acquisition. At each location where a depth measurement was taken, the system also captured the boat's GPS location. Both of these pieces of data were logged to a removable micro-SD card for later analysis. The entire process of taking a depth measurement was completed in a maximum of 45 seconds for the maximum design depth.

\section{RESULTS}

Preliminary testing was used to determine the accuracy of the mechanical depth measuring system. Using a large drum in an aquaculture lab allowed for an extremely controlled environment. Thus, the exact depth of the water was known and sediment, waves, or wind would not affect the function of the device. After slight adjustments were made, testing continued at the LSU AquaResearch Lakes, which provided a bottom similar to the wetlands and allowed for determination of how the weight responded to the mud. Additionally, this environment allowed the influence of wind and slight waves on the depth measurement to be monitored. The boat was allowed to function for an extended time in the lakes to determine whether it could function without any human involvement.

Accurate readings were obtained from testing in the aquaculture lab off a $0.762 \mathrm{~m}$ high table. One count from the IR emitter and detector equaled a distance of $3.8 \mathrm{~cm}$. For the readings off the table, a range of 19-21 counts was obtained, with an error of $\pm 3.05 \mathrm{~cm}$. After these initial table top 
tests, the boat was tested in a controlled tank. The error increased to $\pm 3.3 \mathrm{~cm}$. Each measurement was off by approximately $7.6 \mathrm{~cm}$, so the measurement system was modified to prevent this from occurring by inserting a PAUSE command, which delayed counting until the weight was in the water and adjusted the depth measurement appropriately. The final test was done in the Aquaculture Research Center Lake. The boat was placed into the water and the entire program was run. These readings gave an error of $\pm 3.6 \mathrm{~cm}$. Multiple trials were run at each different testing site. The table top tests resulted in a standard deviation of 1.255. Testing done in the controlled aquaculture tank resulted in standard deviation of 0.55. The trials at the LSU Aquaculture Research ponds resulted in a standard deviation of 1.403. Figure 4 shows a comparison between the measured depth and actual depth for the Aquaculture Research Center Lake.

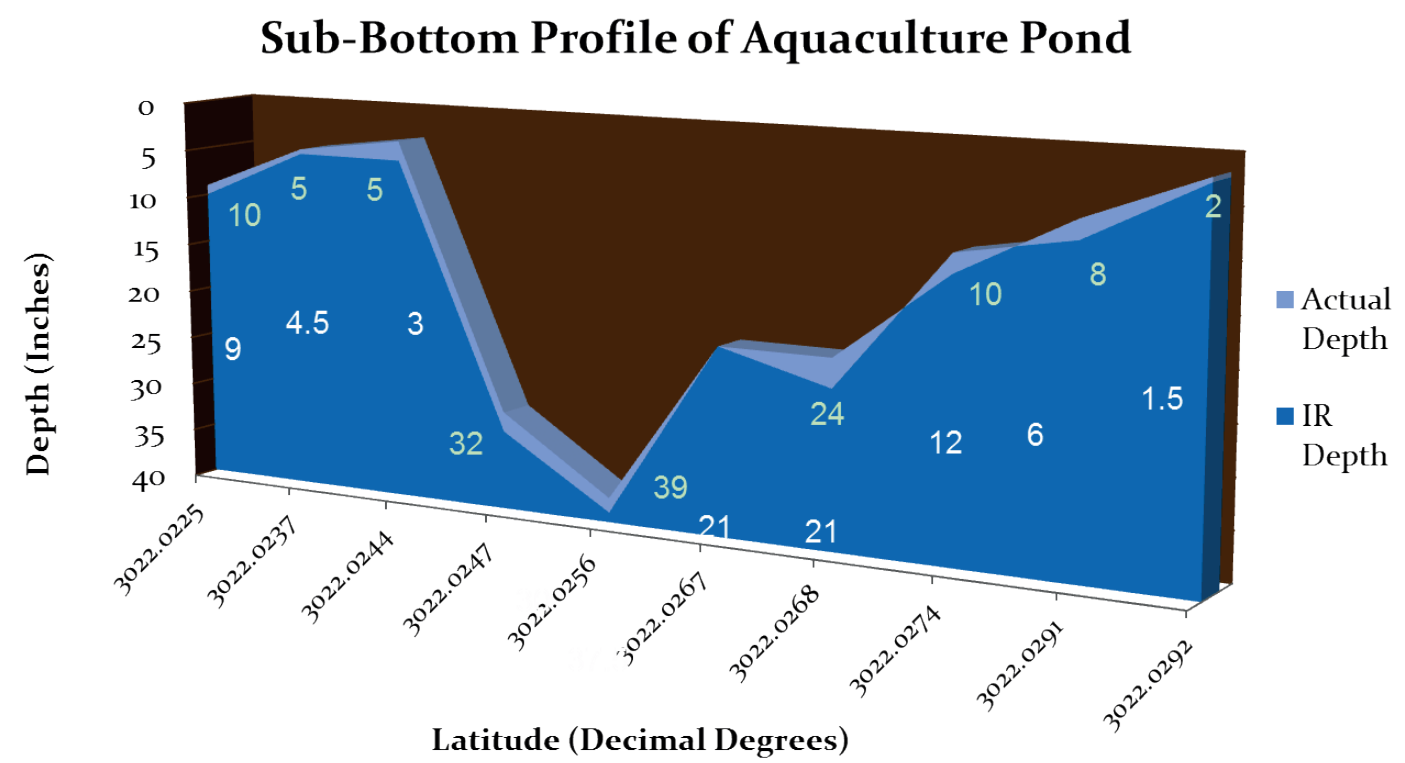

Fig. 4 Sub-bottom profile comparison between actual depth and depth measured with designed depth measuring device.

With the goal of a green design, the boats can be restored, instead of having to be replaced. The solar panels and aluminum frame have a lifespan around 30 years, so they will be re-usable for many years. Depending on the usage frequency of the boat, the batteries will need to be replaced to maintain the optimum charge, but they have an estimated lifespan of 1-6 years. The electronics will also need replacement after a few years. The harsh environment can cause corrosion to occur even though they are in waterproof cases. Also, improvements in electronics will cause the equipment to need upgrading. The foam pontoons are expected to be the limiting component for the overall lifespan because they will be continuously submerged in the water. Even with the water-resistant foam coating, water will still be able to seep into the foam over time, and any wear and tear on the coat can help accelerate this process. With the lifespan of each component taken into consideration, the expected lifespan for the combined boat and depth measuring device is up to five years. Each component will be properly disposed of at the end of its useful life depending on regulations.

\section{DISCUSSION}

The bottom was defined based on the consistency and repeatability of the measurements. The maximum error exceeded the design goal of 1 inch $(2.54 \mathrm{~cm})$, but the boat was still accurate enough to help monitor the coastal restoration and erosion rates. The bearing pressure can be customized by changing the mass and/or surface area of the testing device. This allows the overall 
device to operate in very shallow water and measure soft sediment with reasonable accuracy. Further improvements may improve measurement accuracy further.

\section{CONCLUSION}

The goal of this project was to design and construct a semi-autonomous boat with accurate depth measuring capabilities using mechanical components. It is intended for use in the wetlands for mapping the depth to determine erosion rates and restoration effects. Based on the results obtained, the boat provided an inexpensive, reliable way to map the bottom of the wetlands to determine coastal erosion rates and the productivity of restoration efforts. The uncertainty $3.6 \mathrm{~cm}$ measured from testing at the LSU aquaculture research ponds would still give very accurate results and prove that the concept designed will work.

The boat system provides storage of the data collected, battery life that can last from dusk until dawn and withstand repeated use, measurements within $2.5 \mathrm{~cm}$ accuracy taken every $10 \mathrm{~m}$, and depth measurements up to $4 \mathrm{~m}$. Each measurement is completed in less than 45 seconds, so approximately 400 measurements can be taken per day. The boat is designed to be able to be on the water for 2-day increments, powered by solar panels during the day and hibernating at night.

\section{FUTURE WORK}

The boat system could greatly be improved given better machining abilities. This would allow better accuracy than the $3.6 \mathrm{~cm}$ uncertainty obtained from pond testing. Ongoing work with improved sensing may bring the accuracy to below $1 \mathrm{~cm}$. Additionally, a pulley system with a higher mechanical advantage could be designed so that less power is required from the motor for lowering and raising the line. This would allow allocation of more power for other components on the boat, such as the propulsion system. Future plans also include creating a fleet of boats that could communicate through GPS and map large areas quickly. The addition of a sonar sub-bottom profiler could also provide data between depth readings and would thus be beneficial to the mapping.

Acknowledgements The authors would like to thank faculty, staff and students of the department of Biological and Agricultural Engineering, Louisiana State University, Louisiana, USA.

\section{REFERENCES}

Broggi, A, Bertozzi, M. \& Fascioli, A. (2000) Architectural issues on vision-based automatic vehicle guidance: the experience of the ARGO Project. Real-Time Imaging 4, 313-324.

Dahl, T. E. (2006) Status and trends of wetlands in the conterminous United States 1998-2004. US Fish and Wildlife Service, Washington, DC.

Damuth, J., et al. (1988) Anatomy and growth pattern of Amazon deep-sea fan as revealed by long-range side-scan sonar (GLORIA) and high-resolution seismic studies. The American Association of Petroleum Geologists Bulletin 72, 885-911.

Gerhards, H., et al. (2008) Continuous and simultaneous measurement of reflector depth and average soil-water content with multichannel ground-penetrating radar. Geophysics $73,15-23$.

Glick, P., et al. (2013) Potential effects of sea-level rise on coastal wetlands in southeastern Louisiana. Journal of Coastal Research, doi:10.2112/SI63-0017.1

Hall, S.G. \& Price, R.P. (2003) An autonomous scareboat to reduce bird predation on aquaculture ponds. Louisiana Agriculture $46(1), 4-6$.

Hall, S.G., et al. (2005) Use of autonomous vehicles for improving sustainability via water quality and biological pest management. Presented at ASABE International Meeting (Tampa, FL, July 2005), Paper Number 054147, ASAE, St. Joseph, MI.

Hall, S. G., et al. (2006) Autonomous vehicles to measure water quality in multiple dimensions in coastal areas. In: Coastal Environment and Water Quality (ed. by Xu, Y.J. and V. P. Singh), 285-292. Water Resources Publications.

Hall, S., D. et al. (2007a) Use of autonomous vehicles to enhance water quality in drinking water reservoirs. ASABE International Centennial Meeting Paper \#077055, Minneapolis, MN, June 2007.

Hall S., R. et al. (2007b) Unique applications of automated vehicles in aquaculture. World Aquaculture 38, $45-46$.

Hall, S.G., et al. (2009) Autonomous vehicles in fisheries and aquaculture, In: Biotechnology in Fisheries and Aquaculture (ed. by Thangadurai, N.).

Hoge, F.E., Swift, R. \& Frederick, E. (1980) Water depth measurement using an airborne pulsed neon laser system. Applied Optics 1980, 871-883.

Jeon, H. \& Tian, L. (2009) Direct application end effector for a precise weed control robot. Biosystems Engineering doi:10.1016/j.biosystemseng.2009.09.005 
Kim, S.C., et al. (2000) Development of an unmanned tractor with autonomous and remote control utility. Transactions in $A S A E$, Paper no. 001065.

La Peyre, M.K., et al. (2014) Oyster reef restoration in the northern Gulf of Mexico: Extent, methods, and outcomes. Ocean and Coastal Management 89, 20-28.

Lindgren, D.R., et al. (2002) Relating torque and slip in an odometric model for an autonomous agricultural vehicle. Autonomous Robots 13, 73-86.

Noguchi, N., et al. 1999. Vision intelligence for mobile agro-robotic system. Journal of Robotics and Mechatronics 11, 193199.

Piazza, B.P. et al. (2005) The potential for created oyster shell reefs as a sustainable shoreline protection strategy in Louisiana. J. Restoration Ecology 13(3), 499-506.

Price, R. \& Hall, S.G. (2002) Development of an autonomous boat for bird reduction on aquaculture ponds. ASAE Meeting Paper and Presentation Paper No. 023110, Chicago, IL.

Price, R. \& Hall, S. (2012) Design, development and testing of an autonomous boat to reduce predatory birds on aquaculture ponds. Biological Engineering Transactions 5(2), 61-70.

Price, R., Hall, S.G. \& Allen, D. (2006) Autonomous bird predation reduction device, 2005. US Patent 7,052,348.

Price, R.P., Hall, S. \& Wei, L. (2001) Design of an autonomous bird predation reduction device. ASAE International Meeting, ASAE St. Joseph, MI, Paper no. 01-3131.

Risinger, J.D. (2012) Biologically dominated engineered coastal breakwaters. PhD Dissertation, Louisiana State University. http://etd.lsu.edu/docs/available/etd-07032012-120846/

Smith, D.D., et al. (2014) Use of autonomous surface vehicles for coastal applications. Abstract, ASABE 2014, Montreal Canada.

Smith, D. (2011) Design, development, and testing of a multi-agent autonomous surface fleet for environmental applications. MS Thesis, Louisiana State University. http://etd.lsu.edu/docs/available/etd-07052011-133220/

Swann, L. (2008) The use of living shorelines to mitigate the effects of storm events on Dauphin Island, Alabama, USA. American Fisheries Society Symposium 2008.

Tang, L., Steward, B. \& Tian, L. (2000) Machine vision-based high-resolution weed mapping and patch-sprayer performance simulation. SAE Transactions-Journal of Commercial Vehicles 108, 317-326.

Wang, H., Zu, L. \& Yue, F. (2004) Neural networks-based terrain acquisition of unmarked area for robot mowers. ICARCV 04, 735-740). 